Article

\title{
Sex and SP-A2 Dependent NAD(H) Redox Alterations in Mouse Alveolar Macrophages in Response to Ozone Exposure: Potential Implications for COVID-19
}

\author{
He N. Xu ${ }^{1,+} \oplus$, Zhenwu Lin ${ }^{1,+}$, Chintan K. Gandhi ${ }^{2}$, Shaili Amatya ${ }^{2}$, Yunhua Wang ${ }^{2}$, \\ Lin Z. Li ${ }^{1, *(D)}$ and Joanna Floros ${ }^{3, *}$ \\ 1 Britton Chance Laboratory of Redox Imaging, Department of Radiology, Perelman School of Medicine, \\ University of Pennsylvania, Philadelphia, PA 19104, USA; hexu2@pennmedicine.upenn.edu (H.N.X.); \\ zxl13@psu.edu (Z.L.) \\ 2 Department of Pediatrics, Center for Host Defense, Inflammation, and Lung Disease, College of Medicine, \\ The Pennsylvania State University, Hershey, PA 17033, USA; cgandhi@pennstatehealth.psu.edu (C.K.G.); \\ samatya@pennstatehealth.psu.edu (S.A.); ywang@psu.edu (Y.W.) \\ 3 Departments of Pediatric and Obstetrics and Gynecology, College of Medicine, The Pennsylvania State \\ University, Hershey, PA 17033, USA \\ * Correspondence: linli@pennmedicine.upenn.edu (L.Z.L.); jfloros@psu.edu (J.F.) \\ + These authors contributed equally to the work.
}

Received: 30 July 2020; Accepted: 19 September 2020; Published: 25 September 2020

\begin{abstract}
Co-enzyme nicotinamide adenine dinucleotide (NAD $(\mathrm{H})$ ) redox plays a key role in macrophage function. Surfactant protein (SP-) A modulates the functions of alveolar macrophages (AM) and ozone $\left(\mathrm{O}_{3}\right)$ exposure in the presence or absence of SP-A and reduces mouse survival in a sex-dependent manner. It is unclear whether and how $\mathrm{NAD}(\mathrm{H})$ redox status plays a role in the innate immune response in a sex-dependent manner. We investigated the $\mathrm{NAD}(\mathrm{H})$ redox status of AM from SP-A2 and SP-A knockout (KO) mice in response to $\mathrm{O}_{3}$ or filtered air (control) exposure using optical redox imaging technique. We found: (i) In SP-A2 mice, the redox alteration of AM in response to $\mathrm{O}_{3}$ showed sex-dependence with $\mathrm{AM}$ from males being significantly more oxidized and having a higher level of mitochondrial reactive oxygen species than females; (ii) AM from KO mice were more oxidized after $\mathrm{O}_{3}$ exposure and showed no sex differences; (iii) AM from female $\mathrm{KO}$ mice were more oxidized than female SP-A2 mice; and (iv) Two distinct subpopulations characterized by size and redox status were observed in a mouse $A M$ sample. In conclusions, the $\mathrm{NAD}(\mathrm{H})$ redox balance in $\mathrm{AM}$ responds to $\mathrm{O}_{3}$ in a sex-dependent manner and the innate immune molecule, SP-A2, contributes to this observed sex-specific redox response.
\end{abstract}

Keywords: optical redox imaging; nicotinamide adenine dinucleotide (NAD $(\mathrm{H})$ ); oxidized flavoprotein containing flavin adenine dinucleotide (FAD); redox ratio; surfactant protein A2 (SP-A2); surfactant protein A; macrophage activation; ozone; redox heterogeneity; innate immunity; lung

\section{Introduction}

In the lung, more than $80 \%$ of cells in the bronchoalveolar lavage (BAL) are macrophages [1,2]. Macrophages engulf and digest cellular debris, cancer cells, foreign substances, and bacteria by phagocytosis. Macrophages play a critical role in nonspecific defense (innate immunity) and are important as antigen presenters to T cells [3]. Macrophages also play important pro-inflammatory and anti-inflammatory roles depending on the specific conditions and modulate immune reactions through cytokine release [4]. 
Metabolism has profound influence on macrophage polarization/activation and pathogenesis [5]. Macrophage activation is critically supported by metabolic shifts. Pro-inflammatory macrophages have an anaerobic metabolic profile based on glycolysis whereas anti-inflammatory macrophages generally rely on oxidative phosphorylation (OXPHOS) for energy generation [6,7]. Nicotinamide adenine dinucleotide $\left(\mathrm{NAD}^{+}\right.$and the reduced form $\mathrm{NADH}$, denoted as $\mathrm{NAD}(\mathrm{H})$ ) is an essential co-enzyme for hundreds of reactions within the cell [8]. A change in the $\mathrm{NAD}^{+} / \mathrm{NADH}$ ratio (redox shift) can profoundly affect metabolism, including reactions of glycolysis and the tricarboxylic acid cycle (TCA) and OXPHOS. NAD $(\mathrm{H})$ is also a key mediator in metabolic network, and an $\mathrm{NAD}^{+}$-coupled redox status shift has been demonstrated upon activation of macrophages [9]. Ozone $\left(\mathrm{O}_{3}\right)$ exposure accelerates glycolysis in macrophages which requires constant re-oxidation of NADH [10].

As an essential electron donor, NADH (and the reduced nicotinamide adenine dinucleotide phosphate (NADPH)) is intrinsically fluorescent and emits blue light $(\sim 450 \mathrm{~nm})$ upon the excitation by UV light ( $\sim 360 \mathrm{~nm})$. Another intrinsically fluorescent molecule, flavin adenine dinucleotide (FAD), is an oxidized cofactor of flavoproteins that catalyze a wide range of biological redox reactions. FAD emits green light $(\sim 520 \mathrm{~nm})$ when being excited by blue light $(\sim 430 \mathrm{~nm})$. NADH and FADH $\mathrm{FH}_{2}$ (the reduced form of FAD) are fed into the electron transport chain in mitochondria to generate adenosine- $5^{\prime}$-triphosphate by OXPHOS. Pioneered by Chance et al. [11-15], optical redox imaging (ORI) detects the intrinsic fluorescence signals of NADH and Fp (oxidized flavoproteins containing FAD) and provides the optical redox ratio, Fp/NADH or the normalized redox ratio, Fp/(NADH+Fp). The redox ratio provides a measure of mitochondrial redox state. It has been shown that Fp/NADH and $\mathrm{Fp} /(\mathrm{NADH}+\mathrm{Fp})$ linearly correlate with the biochemically determined $\mathrm{NAD}^{+} / \mathrm{NADH}^{2}$ [16] and the mass-spectrometry determined $\mathrm{NAD}^{+} /\left(\mathrm{NADH}+\mathrm{NAD}^{+}\right)[17,18]$, respectively. ORI is sensitive to cellular metabolic changes and reactive oxygen species (ROS) generation $[19,20]$ and has been widely applied to study cellular metabolism and bioenergetics in both normal and diseased tissues [21-23]. ORI is also sensitive to or correlates with the genetic status and responds to genetic modulations (overexpression and knockdown) of oncogenes [17,24-29]. ORI of the fluorescence intensity and lifetime of NADH and FAD has also been shown to identify macrophage activation phenotypes [9,30] and detect metabolic heterogeneity of macrophages within the tumor microenvironment [30].

Surfactant protein A (SP-A), an innate immune molecule in the lung, has a significant impact on the alveolar macrophages $(\mathrm{AM})$ proteome [31,32] and bacterial phagocytosis [33]. Ozone $\left(\mathrm{O}_{3}\right)$-induced oxidative stress in mice with or without SP-A exhibited a sex-dependent effect on mouse survival after bacterial infection $[33,34]$ in lung pneumonia dissemination $[35,36]$, and on markers of inflammation and oxidative stress in the BAL [37]. However, humans (unlike rodents) have two functional genes, SFTPA1 and SFTPA2, encoding SP-A1 and SP-A2 proteins, respectively; and a number of genetic variants have been identified for each gene [38]. SP-A1 and SP-A2 have been shown to differentially affect the AM proteome [39,40], mouse survival and lung function [41,42]. Moreover, after $\mathrm{O}_{3}$-induced oxidative stress, the AM miRNome (full spectrum of micro RNAs expressed in the genome) in mice carrying either SP-A1 or SP-A2 was differentially affected in a sex-dependent manner, with SP-A2 having a major impact on males [43]. In the present study, we built on these previous findings in an attempt to better understand the mechanisms of $\mathrm{O}_{3}$-induced oxidative stress in the presence or absence of SP-A2, from the perspective of AM metabolism using optical redox imaging. Specifically, we found that ozone exposure altered the $\mathrm{NAD}(\mathrm{H})$ redox status of mouse AM in a sex-dependent manner in the presence of SP-A2, and SP-A2 may play a role in females in counteracting $\mathrm{O}_{3}$-induced oxidation by modulating the $\mathrm{NAD}(\mathrm{H})$ redox status.

\section{Materials and Methods}

\subsection{Study Mice}

All the mice used in the present study were 9-12 weeks of age. The SP-A2 mice used were generated on the C57BL6/J SP-A (KO) background [44]. The $1 \mathrm{~A}^{0}$ variant, the most common SP-A2 
genetic variant in humans, is used for the current study. The animals were raised and maintained under approved housing in a pathogen-free condition at the Penn State College of Medicine animal facility. Both males and synchronized females (with regard to the estrous cycle) were used in this study. The Penn State University College of Medicine Institutional Animal Care and Use Committee approved all procedures involving animals (ethical protocol code 44968).

In this study, a total of 31 mice ( $16 \mathrm{KO}$ mice and $15 \mathrm{SP}-\mathrm{A} 2$ mice) were used for ORI. Among the 16 SP-A KO mice, 7 mice ( 4 males and 3 females) were exposed to filtered air (FA) as control, and 9 mice ( 5 males and 4 females) were exposed to ozone. Among the 15 SP-A2 mice, 6 mice ( 3 males and 3 females) were exposed to filtered air, and 9 mice ( 5 males and 4 females) were exposed to ozone (Table S1).

\subsection{Ozone Exposure and AM Isolation}

SP-A2 $\left(1 \mathrm{~A}^{0}\right)$ or KO male and female mice were exposed to 2 ppm ozone at room temperature and $50 \%$ humidity for $3 \mathrm{~h}$, as described previously [45]. All ozone exposures and filtered air exposures were conducted in parallel [46]. Mice were sacrificed at $4 \mathrm{~h}$ after exposure and subjected to BAL for isolation of alveolar macrophages, as described previously [39]. In brief, AM were obtained by performing BAL with $1 \mathrm{mM}$ EDTA in PBS, using a volume equal to lung capacity $(0.5 \mathrm{~mL} \times 6$ times, a total of $3 \mathrm{~mL})$. The fluid, each $0.5 \mathrm{~mL}$, was instilled and withdrawn 3 times with chest massage during withdrawal. The lavage was kept on ice while being transferred from Penn State University to the University of Pennsylvania for optical redox imaging as described below. The time lapse from BAL to arriving at the optical redox imaging lab was $\sim 3.5 \mathrm{~h}$.

\subsection{Optical Redox Imaging and Data Analysis}

AM in lavage were spun and resuspended in RPMI1640 supplemented with 10\% FBS. The cell resuspension was then seeded on a $35 \mathrm{~mm}$ glass-bottom dish (Mat-Tek or CellVis) and incubated at $37^{\circ} \mathrm{C}, 5 \% \mathrm{CO}_{2}$ for $\sim 3 \mathrm{~h}$. Approximately $10 \mathrm{~min}$ before imaging, the cells were rinsed with PBS (with $\mathrm{Ca}^{2+}$ and $\mathrm{Mg}^{2+}$ ) twice, followed by the addition of $1 \mathrm{~mL}$ of Live Cell Imaging Solution (LCIS, Life Technologies) spiked with glucose (final concentration $11 \mathrm{mM}$ ) for imaging.

For FA-exposed SP-A2 mice, after imaging of the redox baseline, redox plasticity [47] was imaged by sequentially adding mitochondrial metabolic perturbation drugs to first uncouple mitochondrial oxidative phosphorylation then inhibit the mitochondrial complex I and III. Trifluoromethoxy carbonylcyanide phenylhydrazone (FCCP, $0.5 \mu \mathrm{M})$ was used as the uncoupler and a mixture of rotenone $(1 \mu \mathrm{M})$ and antimycin A $(1.25 \mu \mathrm{g} / \mathrm{mL})$ (ROTAA) was used as the inhibitor. Images were taken approximately 3-5 min post addition of each chemical agent.

Mitochondrial ROS was measured by adding MitoSOX red ( $2 \mu \mathrm{M}$ final) to dishes and incubating at $37^{\circ} \mathrm{C}$ (protected from light) for $10 \mathrm{~min}$. Dishes were then rinsed once with PBS and added $1 \mathrm{~mL}$ LCIS supplemented with $11 \mathrm{mM}$ glucose for imaging.

A Zeiss wide field microscope (Axio Observer 7) set at $37^{\circ} \mathrm{C}$ was used for imaging. Images were taken using a 20X objective (0.8 NA). NADH signals were collected through the following optical bandpass filters: excitation (Ex) 370-400 nm and emission (Em) 414-450 nm. Fp signals were acquired with Ex 450-488 nm and Em 500-530 nm bandpass filters. Transmitting (white) light was used to locate and focus on regions of interest to avoid photo-bleaching. Five to ten randomly selected non-overlapping fields of view (FOVs) per dish were imaged with shading corrections on the fly. The image size is $1920 \times 1216$ (pixel size $0.29 \mu \mathrm{m}^{2}$ ). For imaging MitoSOX signals, the cells were excited at $385 \pm 15 \mathrm{~nm}$ and detected at $595 \pm 15 \mathrm{~nm}$.

Acquired images were processed with a customized routine of Matlab ${ }^{\circledR}$. Details of data analysis can be found in our previous reports [25,47]. In brief, the cell-free background signals were subtracted from each of the raw images. A signal-to-noise ratio threshold of 7.5 was further applied to exclude the low-intensity pixels, where noise is defined as the standard deviation in the background. The redox ratio Fp/(NADH+Fp) images were generated pixel-by-pixel using NADH and Fp images. The net mean values of each of the redox indices (NADH, Fp, and the redox ratio) of each FOV were averaged 
to obtain the dish mean and further averaged across dishes to obtain group means (Table S1). The redox indices for AM from one KO male (mouse ID 12273) in the ozone-exposed group deviated by two standard deviations from the group means and thus were considered an outlier and excluded for comparisons between groups.

Statistical analysis was performed with either Student's $t$-test assuming unequal variance or ordinary one-way ANOVA with post-hoc Bonferroni correction for multiple comparisons using PRISM 8. For each redox index, we pooled the data from all groups (sex, exposure, and SP-A2 status) for ANOVA to determine the sex, ozone, and SP-A2 effects on the NAD $(H)$ redox status. The results are presented as mean \pm standard deviation (SD). $p<0.05$ is considered statistically significant. Significant differences are displayed as: ${ }^{*} p<0.05,{ }^{* *} p<0.01,{ }^{* *} p<0.001$, and ${ }^{* * *} p<0.0001$.

\section{Results}

\subsection{Metabolic Responses of AM}

In $\mathrm{KO}$ mice remarkable changes were readily observed in cell morphology of AM after ozone exposure as shown in the representative white light images (Figure 1A). For both males and females, AM from SP-A2 mice appeared to be rounder, fuller, and well separated, whereas AM from KO mice appeared to be irregular shaped and tended to aggregate. For AM from SP-A2 and KO mice under the FA condition, such differences were almost unnoticeable (Figure 1B).

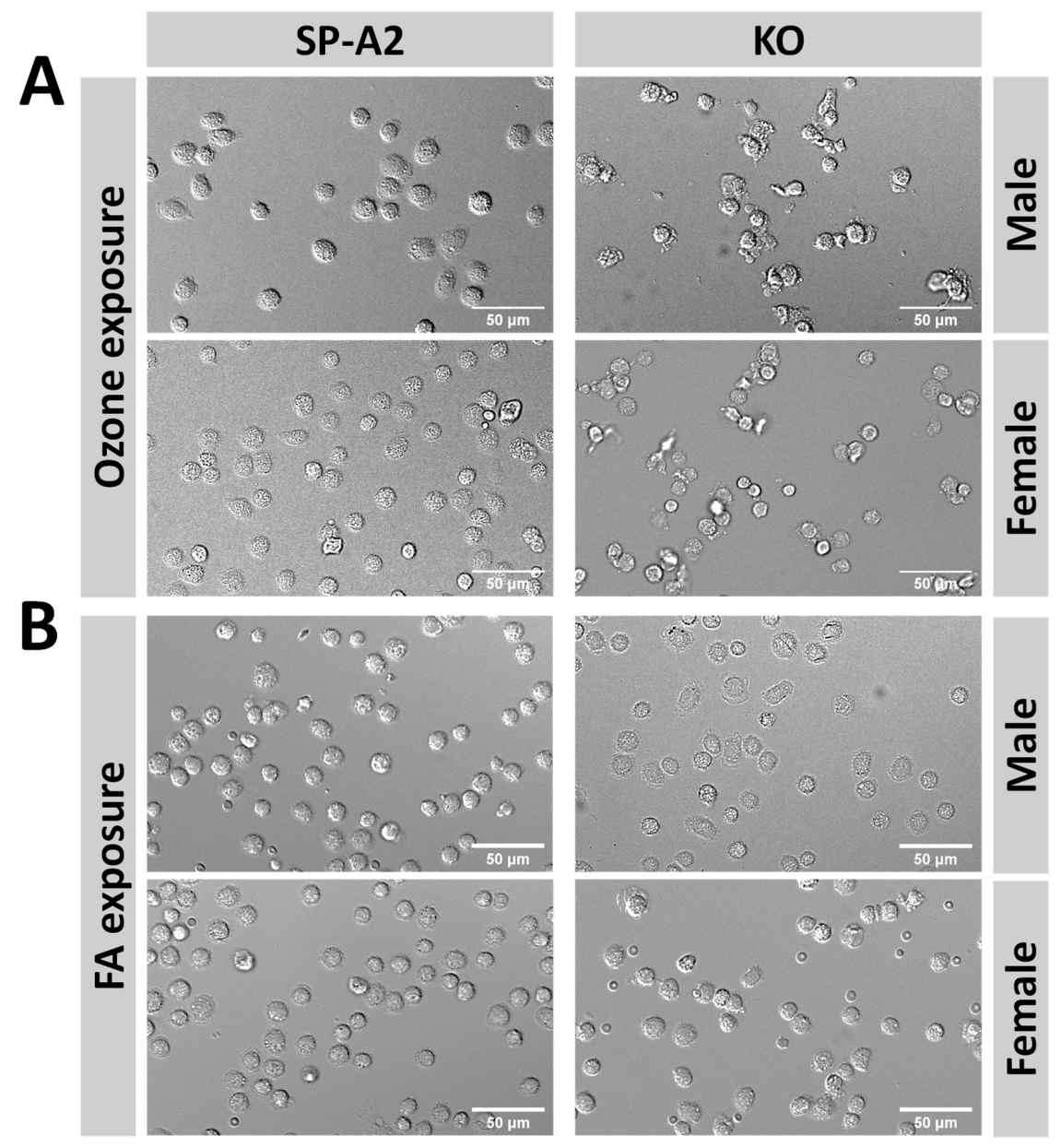

Figure 1. Typical morphological appearance of alveolar macrophages (AM) from SP-A2 and knockout (KO) mice exposed to ozone (A) or FA (B) showing distressed cell morphology of AM from both male and female $\mathrm{KO}$ mice only after ozone exposure. 
We first confirmed that ORI was sensitive to metabolic and redox changes under the experimental settings. After imaging the redox baseline (representative images shown in Figure 2A), we sequentially perturbed the redox status of AM from SP-A2 mice (FA-exposed) with a mitochondrial oxidative phosphorylation uncoupler (FCCP) followed by mitochondrial inhibitors (ROTAA). Treating cells with a mitochondrial oxidative phosphorylation uncoupler such as FCCP should result in a more oxidized state (i.e., higher redox ratio), whereas treating cells with mitochondrial inhibitors such as rotenone (complex I inhibitor) and/or antimycin A (complex III inhibitor) should result in a more reduced state (i.e., lower redox ratio). Using AM from SP-A2 females as an example, after sequentially adding FCCP and ROTAA and imaging accordingly, the ORI signals yielded the expected changes as shown in Figure 2B. Specifically, upon FCCP treatment, the Fp signal significantly increased and the macrophages became significantly more oxidized with a higher optical redox ratio (the oxidized extreme in this study) compared to the baseline; upon subsequent ROTAA treatment, the Fp signal lowered to its baseline level, the NADH significantly increased and the macrophages became significantly more reduced with a lower redox ratio (the reduced extreme) compared to both baseline and FCCP treatment. AM from the male SP-A2 mice exhibited similar changes.
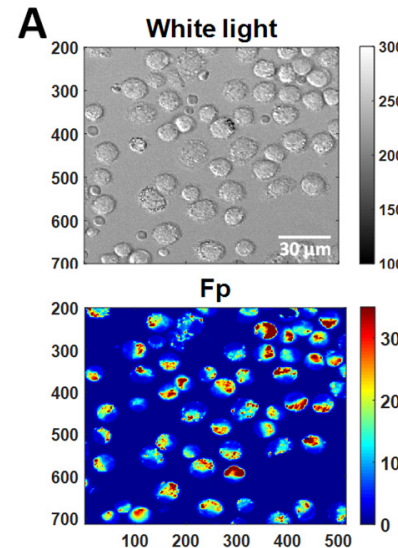

$\begin{array}{lllll}100 & 200 & 300 & 400 & 500\end{array}$

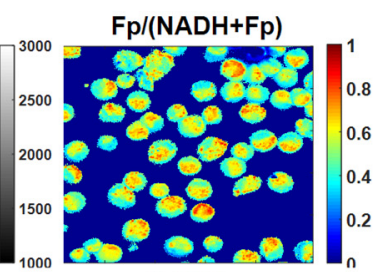

NADH

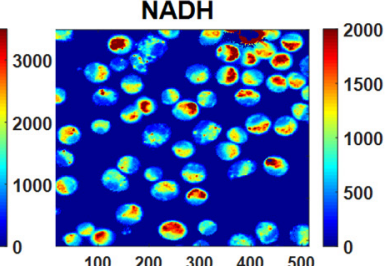

B

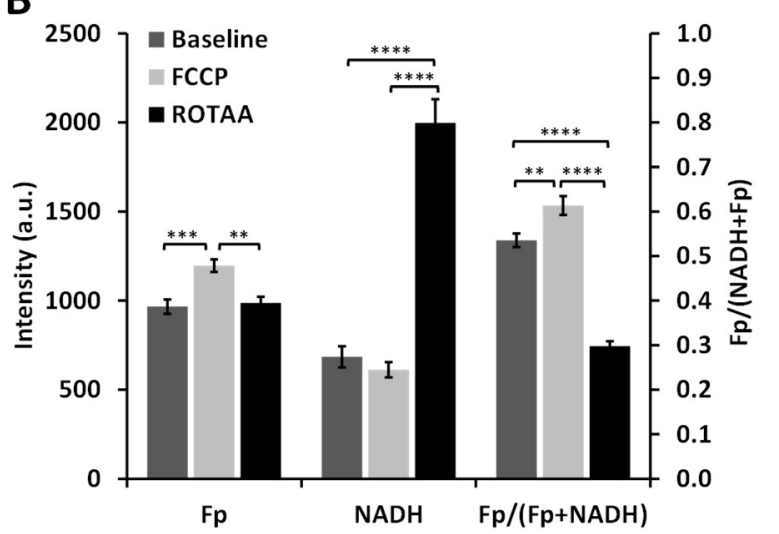

Figure 2. Optical redox imaging (ORI) of alveolar macrophages (AM) is sensitive to metabolic/redox perturbations. (A) Typical white light and redox images of AM from a female SP-A2 mouse (control group, filtered air (FA)-exposed). The grey/color bars to the right side of white light and the Fp and NADH images represent signal intensity in arbitrary units; whereas the color bar for the redox ratio $\mathrm{Fp} /(\mathrm{NADH}+\mathrm{Fp})$ image represents the redox ratio ranging from 0 to 1. (B) Quantitative redox responses of AM from SP-A2 females to the metabolic perturbations by FCCP and ROTAA (Mean \pm SD), confirming that ORI is sensitive to the redox changes under the experimental settings. ${ }^{* *} p<0.01$, *** $p<0.001$, and ${ }^{* * * *} p<0.0001$.

\subsection{Impact of Sex, Ozone, and SP-A2 on AM Redox Status}

We investigated the effect of three main factors, sex, $\mathrm{O}_{3}$ exposure, and SP-A2 (presence or absence), on the NAD $(\mathrm{H})$ redox status of AM. As ozone-induced oxidative stress was shown to differentially affect the AM miRNome of male and female SP-A2 mice, with males being impacted significantly [43], the focus of the present study was on the redox status of AM from the SP-A2 mice.

\subsubsection{Sex Differences under the FA Condition}

Under the FA condition, no significant sex differences were observed in any of the baseline redox indices (Fp, NADH, and the redox ratio) for AM from SP-A2 mice (discussed below). However, when AM from SP-A2 mice were under metabolic stress, the sex difference in the redox indices became significant (Figure 3). Specifically, upon FCCP treatment, which uncouples mitochondrial OXPHOS and pushes the cells to the oxidized extreme, AM from the males were relatively more oxidized than that of the females $(p<0.05)$ (Figure 3A). Upon ROTAA treatment, which inhibits mitochondrial 
complex I and III and pushes the cells to the reduced extreme, AM from the females had relatively less Fp value $(p<0.05)$ (Figure 3B). Besides the redox baseline measures, redox plasticity provides additional information. By calculating the difference in AM from SP-A2 mice between the oxidized and reduced extremes of each redox index as shown in Figure $4 \mathrm{~A}, \Delta \mathrm{Fp}$ (representing the Fp plasticity), $\triangle \mathrm{NADH}$ (representing the NADH plasticity), and $\Delta$ redox ratio $[47,48]$, we quantified the redox plasticity for each redox index and found no significant redox plasticity difference between AM from males and females (Figure 4B). These measurements show that sex difference under the FA condition becomes significant only when AM were subject to metabolic stress and under unperturbed conditions no significant inherent differences could be detected between AM from SP-A2 males and females.
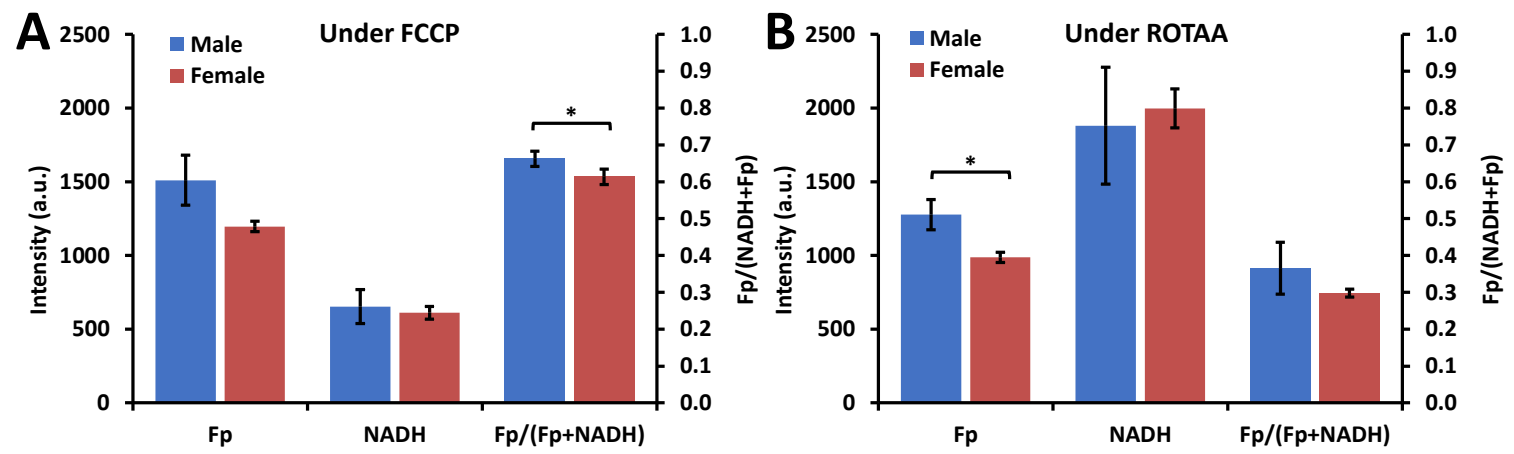

Figure 3. Sex-associated redox difference observed when AM from SP-A2 mice were subject to metabolic stress under the FA condition. (A) AM in the oxidized extreme when treated with mitochondrial oxidative phosphorylation uncoupler FCCP; (B) AM in the reduced extreme when treated with mitochondrial complex I inhibitor (rotenone, ROT) + mitochondrial complex III inhibitor (Antimycin A) $($ Mean $\pm \mathrm{SD}) .{ }^{*} p<0.05$.
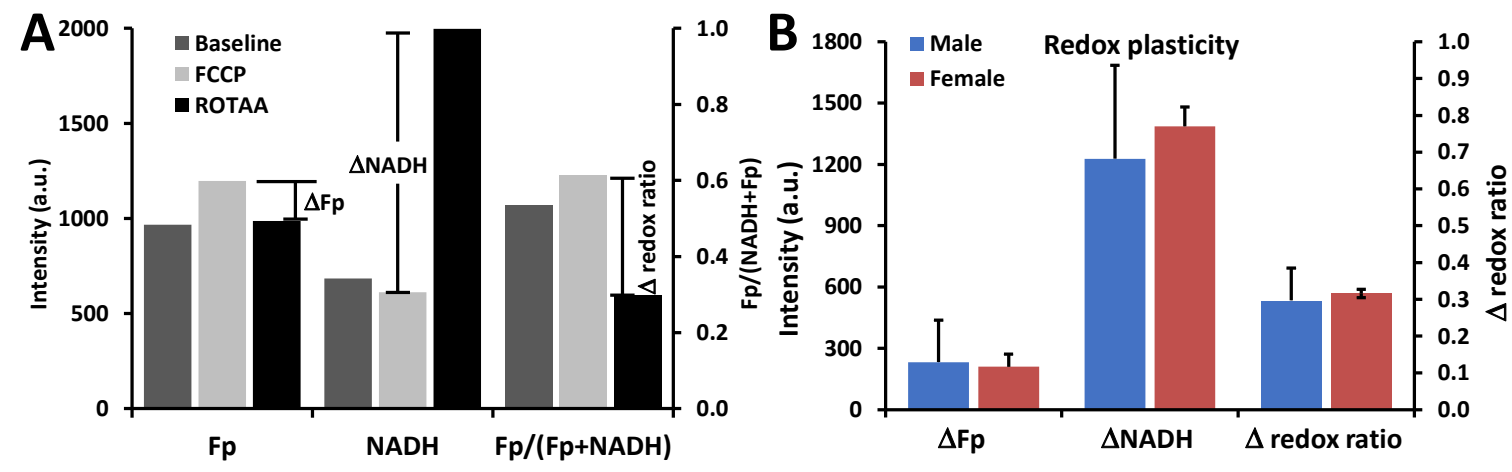

Figure 4. No significant sex-dependent difference in the redox plasticity of SP-A2 AM under the FA condition. (A) Illustration of calculations of redox plasticity, which is the difference between the oxidized (FCCP) and reduced (ROTAA) extremes of the redox indices. The calculation was first performed for AM from each mouse then averaged across the AM samples for each sex group; (B) Redox plasticity of AM from SP-A2 males and females (Mean $\pm \mathrm{SD}$ ).

\subsubsection{Ozone Effect}

As noted above and shown in Figure 5 there was no significant difference in any of the redox indices under the FA condition. In response to ozone exposure the NAD(H) redox status of AM from female SP-A2 mice was not significantly affected (Figure 5). However, in males the NADH level of AM was significantly lowered, indicating that NADH was consumed to counteract ozone-induced oxidative stress. As a result, the cells were shifted to a more oxidized state indicated by significantly higher redox ratio in comparison with that under the FA condition (Figure 5). The redox ratio of AM from male mice was significantly higher compared to AM from female mice under the $\mathrm{O}_{3}$ condition. Thus, 
after $\mathrm{O}_{3}$ exposure, sex-associated redox differences became significant between males and females, as ozone exposure shifted AM from male SP-A2 mice to a more oxidized state with insignificant impact on the AM redox status of female SP-A2 mice.

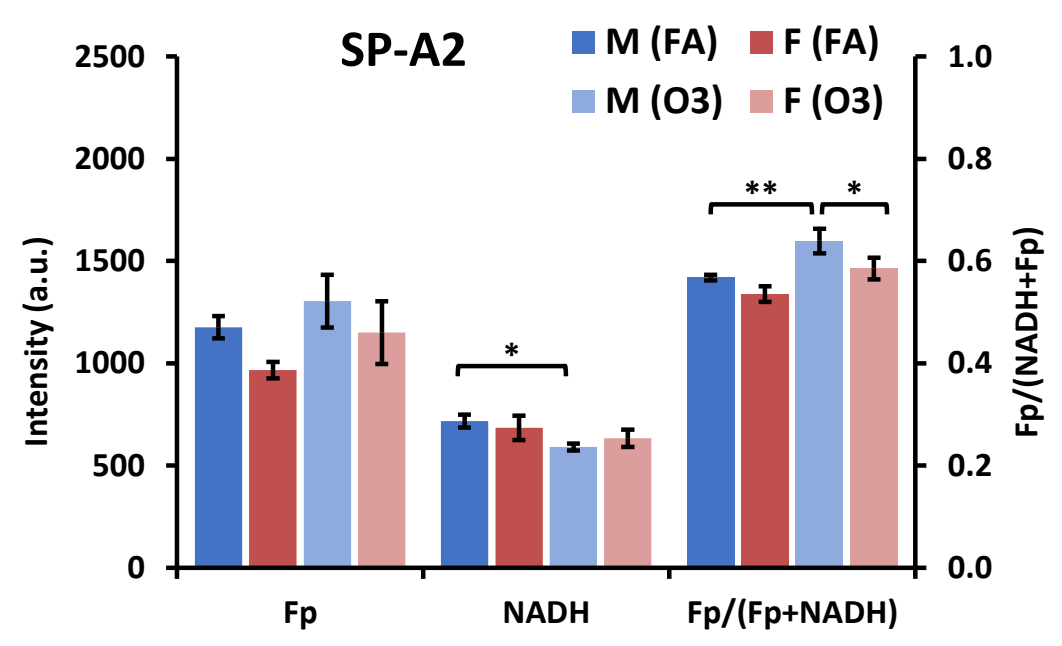

Figure 5. Sex-associated redox difference of AM in SP-A2 mice exposed to FA or $\mathrm{O}_{3}$ (Mean \pm SD). F-female; M-male. ${ }^{*} p<0.05,{ }^{* *} p<0.01$.

In $\mathrm{KO}$ mice, no significant redox difference was observed in AM between male and female mice under the FA condition (Figure 6), similar to that of AM from SP-A2 mice. However, in response to $\mathrm{O}_{3}$ exposure, the Fp significantly increased and so did the redox ratio, regardless of sex in $\mathrm{KO}$ mice (Figure 6).

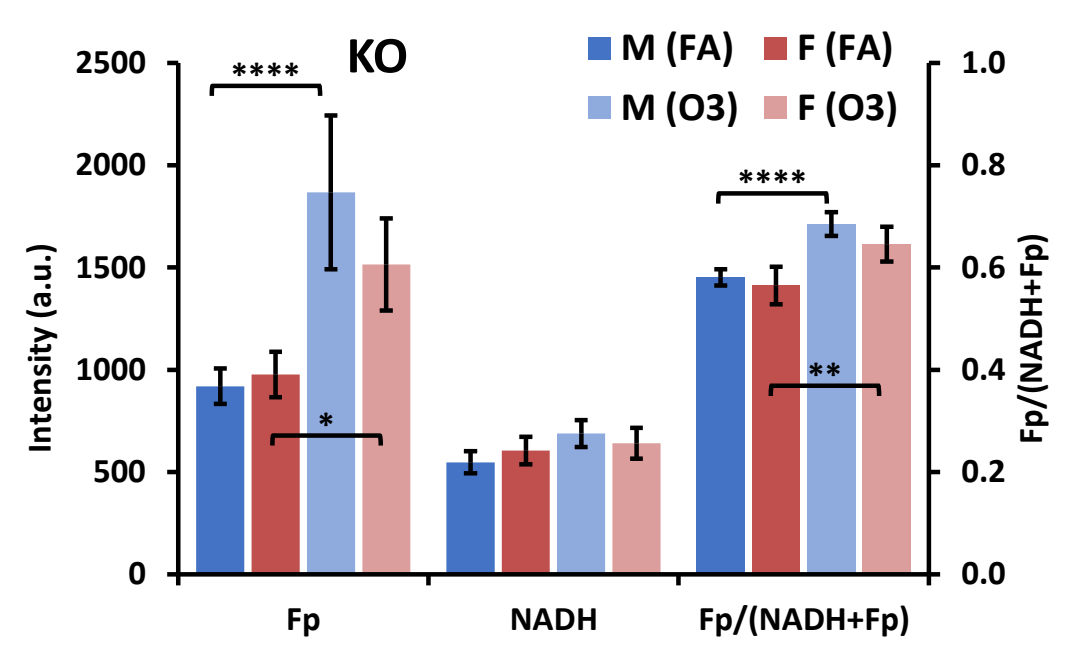

Figure 6. Sex-associated redox difference of $\mathrm{AM}$ in $\mathrm{KO}$ mice exposed to $\mathrm{FA}$ or $\mathrm{O}_{3}$ (Mean $\pm \mathrm{SD}$ ). F-female; M-male. ${ }^{*} p<0.05,{ }^{* *} p<0.01$, and ${ }^{* * * *} p<0.0001$.

As reported in our previous study [19], the $\mathrm{NAD}(\mathrm{H})$ redox status is intricately related to reactive oxygen species (ROS) generation. Since AM from male SP-A2 mice were in a more oxidized state compared to females after ozone exposure, we expected to see a difference in their ROS levels. As shown in Figure 7, under the ozone condition, we indeed found that AM from male mice had $\sim 30 \%$ higher mitochondrial ROS compared to females $(p<0.01)$, positively correlating with the higher redox ratio in AM from males. Since we did not find any significant differences in the redox indices between males and females in $\mathrm{KO}$ mice upon ozone exposure (Figure 6), we did not measure ROS in these groups. 


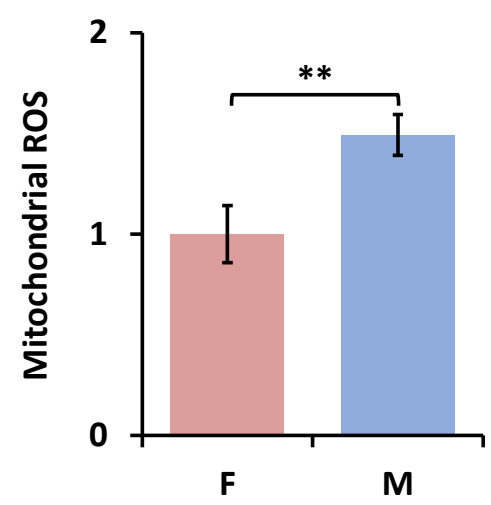

Figure 7. Sex-associated difference in the mitochondrial ROS level (normalized to females) in AM from $\mathrm{SP}-\mathrm{A} 2$ mice exposed to ozone (Mean $\pm \mathrm{SD}$ ). F-female; M-male. ${ }^{* *} p<0.01$.

\subsubsection{SP-A2 Impact on NAD(H) Redox Status}

We next investigated the impact of SP-A2 on $\mathrm{NAD}(\mathrm{H})$ redox status of AM. For male mice, under the FA condition, AM from SP-A2 mice compared to those of KO had $\sim 26 \%$ higher NADH $(p=0.016)$, $\sim 26 \%$ higher Fp $(p>0.99)$ and similar redox ratio (Figure 8A), indicating that SP-A2 may affect mitochondrial density in AM since the majority of ORI signals come from mitochondria. In contrast, after ozone exposure, AM from SP-A2 males had approximately 30\% lower Fp $(p=0.0021), \sim 14 \%$ lower $\operatorname{NADH}(p=0.15)$, and $\sim 6 \%$ lower redox ratio $(p=0.12)$ (Figure $8 \mathrm{~B})$, indicating that SP-A2 may affect AM's anti-oxidative stress capacity. For female mice, under the FA condition, there is no significant difference in any of the redox indices between AM from SP-A2 and KO mice (Figure 8C); however, under the ozone condition, compared to KO, AM from SP-A2 were in a more reduced state, indicated by a $10 \%$ lower redox ratio $(p=0.020)$, despite the fact that no significant change was observed in either Fp ( $24 \%$ lower with $p=0.13)$ or NADH level (Figure $8 \mathrm{D})$. Together, these data indicate that SP-A2 may have a sex-specific role in AM's $\mathrm{NAD}(\mathrm{H})$ redox homeostasis in response to both FA and ozone exposure for males and to ozone exposure for females.
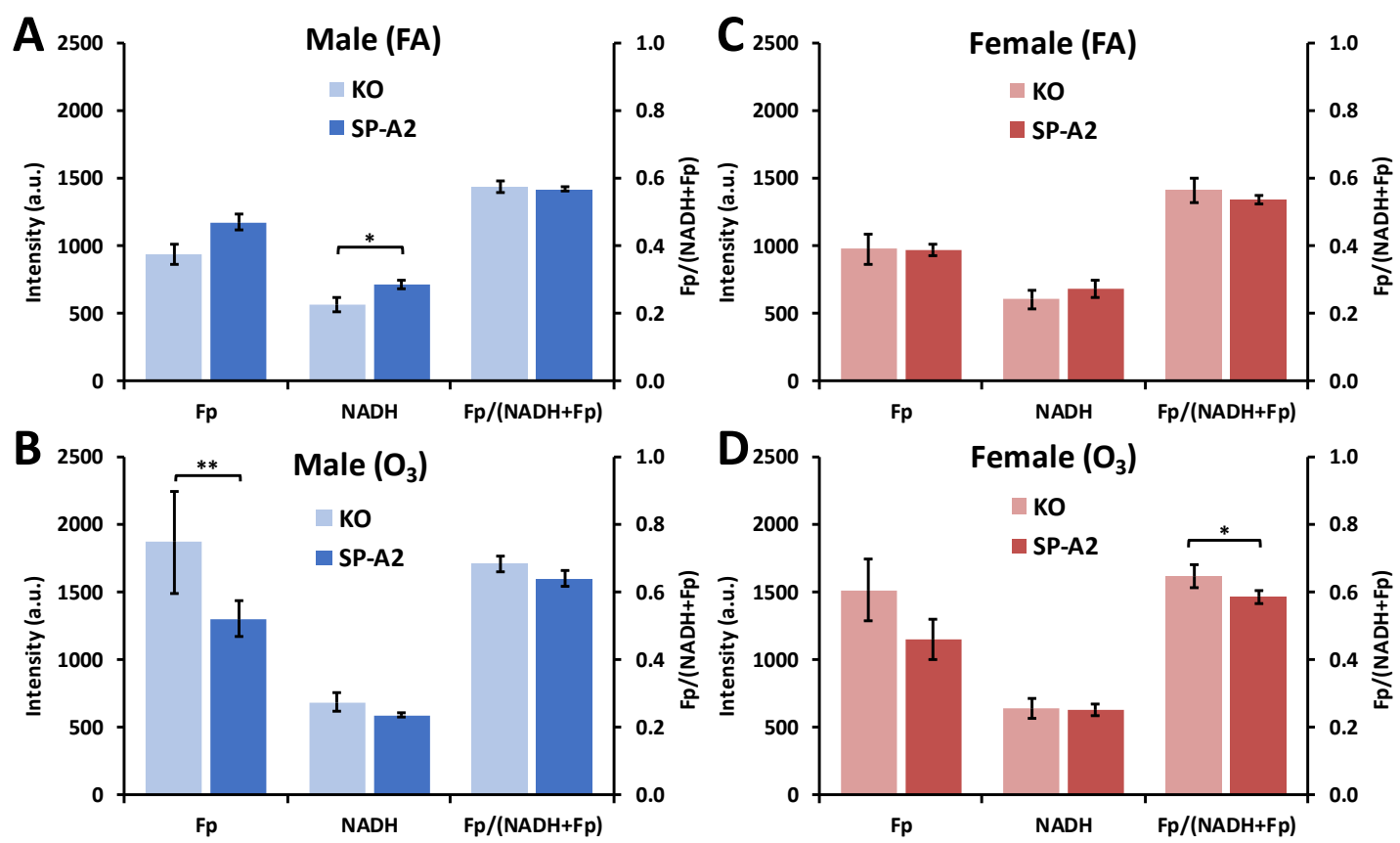

Figure 8. SP-A2-associated redox differences in AM from male $(\mathbf{A}, \mathbf{B})$ and female $(\mathbf{C}, \mathbf{D})$ mice exposed to FA $(\mathbf{A}, \mathbf{C})$ or $\mathrm{O}_{3}(\mathbf{B}, \mathbf{D})($ Mean $\pm \mathrm{SD}) .{ }^{*} p<0.05,{ }^{* *} p<0.01$. 


\subsection{Optical Redox Imaging Detects AM Heterogeneity within an Individual Mouse}

The AM sample from one ozone-exposed male KO mouse (mouse ID 12273) was considered an outlier and its ORI data were omitted from the previous redox group analysis. However, an initial observation of the AM sample from this mouse revealed something very interesting: There existed cells with two distinct sizes (larger and smaller cells), vastly different from all other AM samples. We acquired images of 18 FOVs with each containing more than 100 cells. From both the composite image of NADH and $\mathrm{Fp}$ (Figure 9A) and the white light image (Figure 9B, an enlarged section outlined by the red frame of Figure 9A), one can clearly see the size differences in a typical FOV. Figure $9 \mathrm{C}$ is the redox ratio image of the same FOV (redox ratio images from 3 additional FOVs and their corresponding histograms are shown in Figure S1). These redox ratio images as well as their corresponding histograms clearly depict a bimodal distribution, indicating two distinct redox subpopulations of AM despite of some overlap. We quantified the redox indices of these two subpopulations by selecting 30 AM of the larger size $(\sim 20-30 \mu \mathrm{m})$ and 30 AM of the smaller size $(\sim 10 \mu \mathrm{m})$ from these four FOVs (Figures 9 and S1). Each cell was one region of interest (ROI) (in cases where it was difficult to draw ROI for one single smaller cell, a cluster of smaller cells were included in the ROI). The mean values of the redox indices of the larger and smaller AM averaged across all selected cells are shown in Figure 10. Student's $t$-test analysis showed that the redox differences between the two subpopulations are highly significant $(p<0.0001$ for $\mathrm{NADH}$ and the redox ratio and $p=0.013$ for $\mathrm{Fp}$ ). These data indicate that AM redox heterogeneity can occur within the same mouse, as shown here, where the larger cells were in a more reduced state (lower $\mathrm{Fp}$, higher NADH, and lower redox ratio), and the smaller cells were in a more oxidized state.
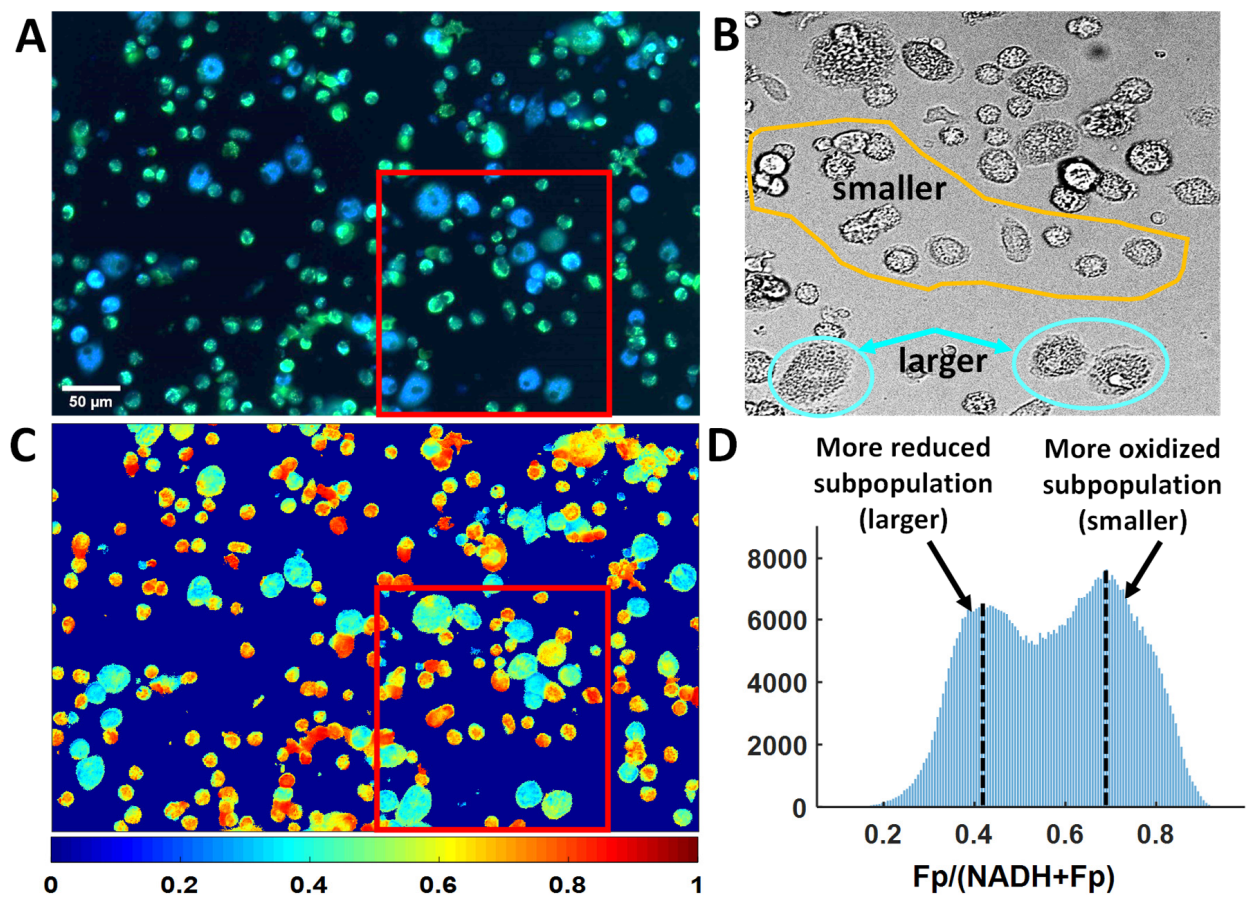

Figure 9. ORI detects AM redox heterogeneity within a male $\mathrm{KO}$ mouse with prior ozone exposure. (A) A representative composite image of NADH (blue) and Fp (green); (B) The white light image of an enlarged area outlined by the red frames in (A) and (C), with some larger and smaller cells encircled in cyan and yellow, respectively; (C) The redox ratio image corresponding to the image in (A), displaying two distinct redox subpopulations readily discerned by their pseudo-colors, i.e., cyan (more reduced state, redox ratio $\sim 0.4$ ) vs yellow-orange (more oxidized state, redox ratio $\sim 0.7$ ). The color bar indicates the redox ratio ranging from 0 to 1 ; (D) The histogram of the redox ratios from the image in (C), clearly shows a bimodal redox state, representing the mixture of a more reduced subpopulation and more oxidized subpopulation, respectively. The $\mathrm{x}$-axis represents the redox ratio (Fp/(NADH+Fp)); $y$-axis represents the number of pixels having a specific redox ratio; dotted line represents the redox ratio of each subpopulation. 


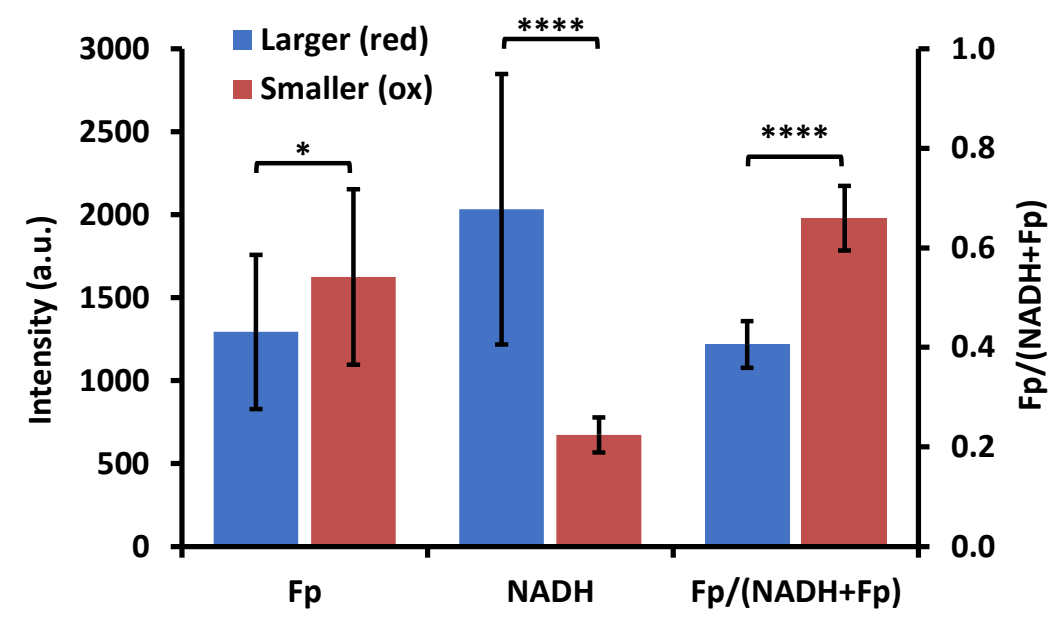

Figure 10. Quantified results for all three redox indices based on 30 cells per subpopulation selected from the four fields of view included those in Figures 9 and S1. ${ }^{*} p<0.05,{ }^{* * * *} p<0.0001$.

\section{Discussion}

Ozone has been shown to be a pulmonary irritant for several species including human, monkey, and rodents, and it can cause oxidative stress in alveolar macrophages [37,45,49-52]. Ozone exposure results in oxidative stress via direct action on its target macromolecules or free radicals formed by peroxidation of lipids and induces cellular and molecular alterations and human diseases including pulmonary injury. Ozone inhalation-induced oxidative stress activates both cytotoxic/pro-inflammatory (M1) and wound repairing/anti-inflammatory (M2) macrophages in the lung $[49,53]$. Macrophage activation is characterized by metabolic shifts and the mitochondria are central hubs in inflammatory macrophage activation [6]. Ozone can accelerate both peroxidative and glycolytic metabolisms in AM [54,55].

The $\mathrm{NAD}(\mathrm{H})$ redox potential $\mathrm{NAD}^{+} / \mathrm{NADH}$ regulates many enzymatic reactions in cell metabolism including glycolysis, the TCA cycle, respiration, and lipid metabolism. The $\mathrm{NAD}(\mathrm{H})$ redox status is intricately related to the balance of cellular reductants and oxidants $[19,20,56]$. The entanglement of the $\mathrm{NAD}(\mathrm{H})$ redox status, sex, and innate immune molecules, such as SP-A2 in AM, has not been reported before, and this was the focus of the present study. We employed optical redox imaging, which is also sensitive to metabolic changes, to study the $\mathrm{NAD}(\mathrm{H})$ redox response of a well-established bronchoalveolar macrophage model from mice exposed to ozone (more than $80 \%$ of the cells in BAL are macrophages [1,2]). Our results indicate that an ozone exposure of $2 \mathrm{ppm}$ for $3 \mathrm{~h}$ resulted in a significantly lower NADH level and higher optical redox ratio in AM from male SP-A2 mice. An early study measuring the metabolite concentrations coupled with the near-equilibrium reactions of $\beta$-hydoxybutyrate dehydrogenase showed that the mitochondrial $\mathrm{NAD}^{+} / \mathrm{NADH}$ ratio in $\mathrm{AM}$ decreases significantly after exposure to $1 \mathrm{ppm}_{3}$ for $5 \mathrm{~h}$ in vitro [57]. However, the quantification of the redox ratio in that study relied on the assumption that mitochondrial $\mathrm{pH}$ remains constant before and after ozone exposure, which might not be valid. Ozone has been shown to oxidize NADH directly in vitro [58] and ROS have been shown to increase the optical redox ratio [19] or the NAD ${ }^{+} / \mathrm{NADH}$ ratio [59]. While more studies are needed to further confirm the effects of ozone on the cellular $\mathrm{NAD}(\mathrm{H})$ redox status, the more oxidized optical redox ratio reported here is consistent with the known effects of the ability of ozone to generate ROS and exhibit oxidation effects. In the present study, we also observed a higher mitochondrial ROS level corresponding to a higher optical redox ratio in AM from SP-A2 male mice than that from female mice after ozone exposure.

In addition, we report here the effects of ozone exposure on the $\mathrm{NAD}(\mathrm{H})$ redox status in the absence of the innate immune molecule, SP-A2, and on the Fp signal, neither of which has been reported before. The Fp signal mainly originates from the oxidized FAD moiety in pyruvate dehydrogenase 
$(\mathrm{PDH})$ and $\alpha$-ketoglutarate dehydrogenase $(\alpha-\mathrm{KGDH})$ in the TCA cycle and the electron-transfer flavoprotein in the electron transport chain, accounting for the majority of the Fp signal while the rest is not substrate reducible and is insensitive to redox metabolism [21,25,60-62]. The Fp signal is commonly observed to change in opposite direction of $\mathrm{NADH}$, which may be explained by the conjugation of the two redox pairs NAD ${ }^{+} / \mathrm{NADH}$ and $\mathrm{FAD} / \mathrm{FADH}_{2}$ in $\mathrm{PDH}$ and $\alpha-\mathrm{KGDH}$ in the TCA cycle. Higher NADH would result in more $\mathrm{FADH}_{2}$ and less FAD and vice versa. Although further studies are needed to identify the exact factors contributing to $\mathrm{Fp}$ signal variation as observed in this study, a significantly higher $\mathrm{Fp}$ signal upon $\mathrm{O}_{3}$ exposure in $\mathrm{AM}$ from $\mathrm{KO}$ mice may indicate a lower NADH level in mitochondria, presumably correlating with a higher level of ROS and oxidative stress. Note that although the NADH signal detected by ORI can be contributed by cytosolic NADH and NADPH as well, these concentrations are expected to be much lower than NADH in mitochondria and ORI mainly reflects mitochondrial NADH [22,63]. Nonetheless, simultaneous increase or decrease of NADH and Fp signals can indicate a change in mitochondrial densities within cells, induced by genetic and/or environmental factors. In contrast, the optical redox ratio is insensitive to mitochondrial density change and reflects the redox balance. A higher optical redox ratio upon ozone exposure in AM from male SP-A2 mice and from $\mathrm{KO}$ mice also indicates an increased mitochondrial bioenergetic activity/oxidative phosphorylation $[30,64]$.

The metabolism differs between M1 (usually pro-inflammatory) and M2 (usually anti-inflammatory) macrophages, and macrophages can switch from an oxidative phosphorylation metabolic profile (M2) to a glycolysis profile (M1), and vice versa [7,9]. Ozone inhalation-induced oxidative stress can induce both M1 and M2 phenotypes in AM [49,53], and M2 macrophages can contribute to chronic inflammatory lung diseases as well [65]. A lower optical redox ratio (more reduced state) has been associated with enhanced glycolysis and M1 macrophages while a higher optical redox ratio (more oxidized state) has been associated with M2 macrophages [30]. A similar relationship between the optical redox ratio and glycolysis/OXPHOS balance was also found in T cell activation [66]. Therefore, the observed increased redox ratio of $\mathrm{AM}$ after ozone exposure indicates that $\mathrm{O}_{3}$ might have induced an $\mathrm{M} 2$ phenotype in $\mathrm{AM}$ from SP-A2 males, whereas, in AM from SP-A2 females this was not or less the case since no statistically significant changes in the redox ratio were observed (Figure 5). However, in the absence of SP-A2, AM from both male and female mice became significantly oxidized and likely assuming an M2 type activation upon ozone exposure, without sex differences (Figure 6). Admittedly, measurements of M2 macrophage biomarkers (e.g., arginase 1 and chi313 [65,67]) are needed to confirm or disapprove this interpretation.

ORI provides a quick imaging tool to probe macrophage activation of single cells. The interesting bi-modal redox status with both higher and lower redox ratio of the two cell subpopulations observed in AM from a male $\mathrm{KO}$ mouse after ozone exposure (Figures 9, 10 and S1) indicates that a heterogeneous macrophage activation can occur in the same BAL sample. While the subpopulation with a higher redox ratio (the smaller cells) is consistent with an anti-inflammatory M2 type activation observed in AM from the other mice, the subpopulation with a lower optical redox ratio (the larger cells) indicates a possible pro-inflammatory M1 type activation (Figures 9, 10 and S1). Based on gene expression analysis, both pro-inflammatory and anti-inflammatory macrophage activation was found in BAL macrophages from human patients of idiopathic pulmonary fibrosis and in an in vitro murine alveolar macrophage model exposed to iron accumulation [1]. Although the cause of this bi-modal redox status in AM in the current study is unknown, the importance of this observation is that this can indeed occur in a single animal, and therefore imaging the $\mathrm{NAD}(\mathrm{H})$ redox status in $\mathrm{AM}$ could serve as an effective tool to more accurately determine the relative activation of macrophages in terms of the pro- and antiinflammatory status. Once different subpopulations can be established by ORI on the single cell level, it would be interesting to perform gene expression analysis of subpopulations after cell sorting based on optical redox ratio or NADH signals [68].

In this study, we observed no significant $\mathrm{NAD}(\mathrm{H})$ redox differences between AM from male and female mice, either with or without SP-A2, exposed to filtered air (Figures 5 and 6). In contrast, 
sex differences became evident after ozone exposure in SP-A2 mice, where a more oxidized redox state (a higher redox ratio) and a higher ROS signal were observed in AM from males compared to females (Figures 5 and 7). However, in the absence of SP-A2, no sex differences were observed in the $\mathrm{NAD}(\mathrm{H})$ redox status in response to ozone (Figure 6), indicating a role of SP-A2 in the observed sex-dependent differences. Sex dependence of redox features in cells and tissues has been reported in the literature $[69,70]$. Females have been found to have more antioxidant capacity and greater resistance to oxidative stress $[69,71]$. Although this is the first time that SP-A and sex dependent differences have been observed in the $\mathrm{NAD}(\mathrm{H})$ redox status of $\mathrm{AM}$, sex differences in $\mathrm{AM}$ in response to SP-A and/or $\mathrm{O}_{3}$ have been seen in other readouts. Consistent with the present findings, previous studies observed that the miRNome of SP-A2 female mice did not change significantly in response to ozone-exposure whereas the AM miRNome in SP-A2 males did [43]. A comparable finding of sex-dependent cellular response after ozone exposure was observed in lung alveolar epithelial type II cells. The miRNome in these cells from SP-A1 female mice did not change significantly but it did in males [72]. Together, these support the notion that at the cellular level females are better prepared to handle oxidative stress in the presence of the innate immune molecule, SP-A2.

The lower mitochondrial NADH in male KO compared to SP-A2 mice (Figure 8A) suggests a higher bioenergetics activity and likely a higher ROS, indicating that oxidative stress may be expected when SP-A2 is not present. Thus, the present results are consistent with a possible protective role of SP-A2 by modulating the $\mathrm{NAD}(\mathrm{H})$ redox status and the oxidative stress after ozone exposure. In fact, it has been previously postulated that SP-A has an antioxidant role in the lung by scavenging ROS [73] or possibly regulating NADPH oxidase activity in human monocyte derived macrophages [74] which may or may not capture the in vivo effect of the ozone-induced oxidative stress in the lungs. It has been shown that the tissue-specific alveolar macrophages differ from monocyte-derived macrophages in response to injury [75,76]. In contrast, SP-A is shown to induce reactive oxygen species and cytokine responses by local AM in response to infection [77]. Moreover, in an earlier report where the bronchoalveolar lavage proteome was studied in response to ozone-exposure in the presence or absence of SP-A, the KO under control conditions (i.e., filtered air exposure) were found to exhibit a response pattern similar to that observed in the wild type mice after ozone exposure [78]. The similarity in response between SP-A KO mice exposed to filtered air and wild type mice exposed to ozone indicates that in the absence of SP-A, KO mice may be in a chronic oxidative stress state. Thus, the collective data provide support for a role of SP-A as antioxidant and the present findings, in particular, indicate that this may occur via $\mathrm{NAD}(\mathrm{H})$ redox changes in a sex-specific manner.

AM sex-dependent differences have also been observed using insults other than ozone, such as infection. These include, following K. pneumoniae infection, SP-A variant and sex-dependent differences in AM gene expression [79], as well as in lung function [42] and survival [41]. Females have been shown to have an overall better outcome in response to a single insult (i.e., infection). This may be due in part to a better-maintained redox homeostasis in females as shown in the present study. Of interest, although ozone, by itself under the experimental conditions used here, is not lethal, if mice after exposure to ozone are also infected with K. pneumoniae, females show a lower survival compared to males $[33,34]$. The underlying mechanisms, except that sex hormones play a role in this differential survival [80], are currently unknown.

The current study has some limitations. First, we have used female mice with synchronized estrous cycles to perform the study. However, the phase of the estrous cycle was not determined. Because the sex hormone profile varies throughout the estrous cycle and can affect lung function and inflammation $[81,82]$ and possibly SP-A2 activity following ozone exposure, future determination of the estrous cycle phase and the sex hormone profile will be valuable. Second, the study of mice exposed to ozone may not entirely reflect the situation in human subjects. Third, we performed this study without virus or bacterial infection. To ultimately understand the molecular links between the role of the $\mathrm{NAD}(\mathrm{H})$ redox status, sex, and SP-A2 in innate immunity and relevant pathologies, we may 
utilize virus/bacteria infected epithelial cells and mouse models in the future. We may also expand the study to human BAL samples.

As a final note, the present findings are potentially relevant to the current COVID-19 pandemic and may provide insight into the role of innate immune molecules, such as SP-A, in oxidative stress and viral host defense and how this may differ between men and women. Correlation between oxidative stress markers and severity of many viral diseases, such as hepatitis $C$ and influenza is well established, but clinical data for SARS-CoV (severe acute respiratory syndrome coronavirus) are limited. However, animal model studies of SARS-CoV infection have shown that activation of ROS production along with innate immunity, transcription factors such as NF- $\mathrm{kB}$, as well as a disturbance in anti-oxidative defense results in an exacerbated pro-inflammatory host response and severe lung injury $[83,84]$. SP-A has been also shown to activate NF- $\mathrm{KB}$ [85], and under baseline conditions and in response to infection with and without prior ozone exposure $[32,39,43,86]$ to affect some of the signaling pathways observed in SARS-CoV infection. Thus, the published information indicates a role of SP-A in various signaling pathways including anti-oxidant pathways that may be relevant to SARS-CoV-2 (severe acute respiratory syndrome coronavirus 2 ) as well, and the present data indicate that the SP-A-mediated $\mathrm{NAD}(\mathrm{H})$ redox status may be one of the mechanisms.

The SARS-CoV-2 causes acute lung injury that may develop into life-threatening acute respiratory distress syndrome in elderly individuals. However, the majority of young patients recover, indicating that protective host responses may be operational to combat the viral infection. Though males and females get infected with SARS-CoV-2 at the same rate, males are at higher risk for severe disease and death, independent of age [87]. The underlying mechanisms and whether it is due to gender and/or sex differences is not known at this time. Given the sex-specific and the SP-A genotype specific outcomes in animal models $[41,42,79,86,88]$ and the important role of innate immunity in providing the first line of defense, it is highly likely that the genetics of the innate immunity molecule, SP-A, contribute to and/or may partly explain the differential outcome in COVID-19 patients under different lung microenvironments $[89,90]$. The genotype- and sex-dependent effect of SP-A on NAD(H) redox status and oxidative stress/inflammatory pathways may be of clinical relevance in COVID-19 patients and SP-A may be considered as a potential therapy. The rationale for this potential therapy is based on the information where SP-A is shown to modulate pathways either under baseline conditions $[32,40]$ or in response to infection and/or ozone exposure $[43,86,88]$ that are deemed important in COVID-19 disease [91]. These include, among others, the Nrf2 and the acute phase response that includes NF- $\mathrm{kB}$ and the IL-6.

In addition, since the pathology of COVID-19 patients is characterized by excessive inflammatory macrophage activation [92], we would expect ORI to be a useful tool. It can be used to evaluate the severity and heterogeneity of macrophage activation in BAL of alveolar macrophages from COVID-19 patients. This may help to better understand the SARS-CoV-2 induced inflammatory macrophage activation and develop interventional approaches to mitigate the inflammation in COVID-19 patients.

\section{Conclusions}

Sex is a significant factor for human health, including immune responses to environmental insults such as air pollution, infection, and others. Our study indicates that the $\mathrm{NAD}(\mathrm{H})$ redox status of alveolar macrophages shifts to a more oxidized state after exposing mice to ozone and SP-A2 countermeasures the ozone oxidation effect in females but not in males. This, to the best of our knowledge, is the first time to show ozone-induced $\mathrm{NAD}(\mathrm{H})$ redox change of mouse AM occurring in a sex-dependent and SP-A2 gene-dependent manner. The findings from this study indicate that SP-A genetics and the $\mathrm{NAD}(\mathrm{H})$ redox status may be entangled in innate immunity and inflammation in a sex-dependent manner. These findings point to possibly new directions for understanding and treating COVID-19. 
Supplementary Materials: The following are available online at http://www.mdpi.com/2076-3921/9/10/915/s1, Figure S1: ORI-detected AM redox heterogeneity within a male $\mathrm{KO}$ mouse with prior ozone exposure shows a bimodal redox state. Table S1: The mean redox indices of the studied mice exposed to filtered air (FA, as control group) or Ozone $\left(\mathrm{O}_{3}\right)$.

Author Contributions: Conceptualization, H.N.X., Z.L., L.Z.L., and J.F.; methodology, H.N.X., Z.L., L.Z.L., and J.F.; software, H.N.X., L.Z.L.; validation, H.N.X.; formal analysis, H.N.X., L.Z.L.; investigation, H.N.X., Z.L., C.K.G., S.A., and Y.W.; resources, L.Z.L. and J.F.; data curation, H.N.X.; writing-original draft preparation, H.N.X., Z.L., J.F., and L.Z.L.; writing-review and editing, H.N.X., Z.L., L.Z.L., J.F., S.A., and C.K.G.; visualization, H.N.X.; supervision: H.N.X., Z.L., L.Z.L., and J.F.; project administration, H.N.X., Z.L., L.Z.L. and J.F.; funding acquisition, L.Z.L. and J.F. All authors have read and agreed to the published version of the manuscript.

Funding: This work was supported by CHILD Research Fund Department of Pediatrics, Pennsylvania State University College of Medicine (J.F.), and by NIH R01CA191207 (L.Z.L.).

Acknowledgments: We thank Annemarie Jacob for her assistance in redox heterogeneity analysis. We also thank the Cell and Developmental Biology (CDB) Microscopy Core, Perelman School of Medicine, University of Pennsylvania.

Conflicts of Interest: The authors declare no conflict of interest.

\section{References}

1. Lee, J.; Arisi, I.; Puxeddu, E.; Mramba, L.K.; Amicosante, M.; Swaisgood, C.M.; Pallante, M.; Brantly, M.L.; Skold, C.M.; Saltini, C. Bronchoalveolar lavage (BAL) cells in idiopathic pulmonary fibrosis express a complex pro-inflammatory, pro-repair, angiogenic activation pattern, likely associated with macrophage iron accumulation. PLoS ONE 2018, 13, e0194803. [CrossRef] [PubMed]

2. Heron, M.; Grutters, J.C.; ten Dam-Molenkamp, K.M.; Hijdra, D.; van Heugten-Roeling, A.; Claessen, A.M.E.; Ruven, H.J.T.; van den Bosch, J.M.M.; van Velzen-Blad, H. Bronchoalveolar lavage cell pattern from healthy human lung. Clin. Exp. Immunol. 2012, 167, 523-531. [CrossRef] [PubMed]

3. Ovchinnikov, D.A. Macrophages in the embryo and beyond: Much more than just giant phagocytes. Genes 2008, 46, 447-462. [CrossRef] [PubMed]

4. Mills, C.D. M1 and M2 Macrophages: Oracles of Health and Disease. Crit. Rev. Immunol. 2012, 32, 463-488. [CrossRef]

5. Thapa, B.; Lee, K. Metabolic influence on macrophage polarization and pathogenesis. BMB Rep. 2019, 52, 360-372. [CrossRef]

6. Langston, P.K.; Shibata, M.; Horng, T. Metabolism Supports Macrophage Activation. Front. Immunol. 2017, 8, 61. [CrossRef]

7. Viola, A.; Munari, F.; Sánchez-Rodríguez, R.; Scolaro, T.; Castegna, A. The Metabolic Signature of Macrophage Responses. Front. Immunol. 2019, 10, 1462. [CrossRef]

8. Goodman, R.P.; Calvo, S.E.; Mootha, V.K. Spatiotemporal compartmentalization of hepatic NADH and NADPH metabolism. J. Biol. Chem. 2018, 293, 7508-7516. [CrossRef]

9. Alfonso-Garcia, A.; Smith, T.D.; Datta, R.; Luu, T.U.; Gratton, E.; Potma, E.O.; Liu, W.F. Label-free identification of macrophage phenotype by fluorescence lifetime imaging microscopy. J. Biomed. Opt. 2016, 21, 046005. [CrossRef]

10. Di Mauro, R.; Cantarella, G.; Bernardini, R.; Di Rosa, M.; Barbagallo, I.; Distefano, A.; Longhitano, L.; Vicario, N.; Nicolosi, D.; Lazzarino, G.; et al. The Biochemical and Pharmacological Properties of Ozone: The Smell of Protection in Acute and Chronic Diseases. Int. J. Mol. Sci. 2019, 20, 634. [CrossRef]

11. Chance, B.; Cohen, P.; Jobsis, F.; Schoener, B. Intracellular oxidation-reduction states in vivo. Science 1962, 137, 499-508. [CrossRef]

12. Chance, B.; Schoener, B. Fluorometric studies of flavin component of the respiratory chain. Flavins Flavoproteins 1966, 81, 510-519.

13. Chance, B.; Baltscheffsky, H. Respiratory enzymes in oxidative phosphorylation. VII. Binding of intramitochondrial reduced pyridine nucleotide. J. Biol. Chem. 1958, 233, 736-739. [PubMed]

14. Quistorff, B.; Haselgrove, J.C.; Chance, B. High resolution readout of 3-D metabolic organ structure: An automated, low-temperature redox ratio-scanning instrument. Anal. Biochem. 1985, 148, 389-400. [CrossRef] 
15. Chance, B.; Schoener, B.; Oshino, R.; Itshak, F.; Nakase, Y. Oxidation-reduction ratio studies of mitochondria in freeze-trapped samples. NADH and flavoprotein fluorescence signals. J. Biol. Chem. 1979, 254, 4764-4771. [PubMed]

16. Ozawa, K.; Chance, B.; Tanaka, A.; Iwata, S.; Kitai, T.; Ikai, I. Linear correlation between acetoacetate/betahydroxybutyrate in arterial blood and oxidized flavoprotein/reduced pyridine nucleotide in freeze-trapped human liver tissue. Biochim. Biophys. Acta 1992, 1138, 350-352. [CrossRef]

17. Varone, A.; Xylas, J.; Quinn, K.P.; Pouli, D.; Sridharan, G.; McLaughlin-Drubin, M.E.; Alonzo, C.; Lee, K.; Munger, K.; Georgakoudi, I. Endogenous two-photon fluorescence imaging elucidates metabolic changes related to enhanced glycolysis and glutamine consumption in precancerous epithelial tissues. Cancer Res. 2014, 74, 3067-3075. [CrossRef] [PubMed]

18. Quinn, K.P.; Sridharan, G.V.; Hayden, R.S.; Kaplan, D.L.; Lee, K.; Georgakoudi, I. Quantitative metabolic imaging using endogenous fluorescence to detect stem cell differentiation. Sci. Rep. 2013, 3. [CrossRef] [PubMed]

19. Podsednik, A.; Jacob, A.; Li, L.Z.; Xu, H.N. Relationship between Optical Redox Status and Reactive Oxygen Species in Cancer Cells. React. Oxyg Species 2020, 9, 95. [CrossRef]

20. Aon, M.A.; Cortassa, S.; O'Rourke, B. Redox-optimized ROS balance: A unifying hypothesis. Biochim. Biophys. Acta 2010, 1797, 865-877. [CrossRef] [PubMed]

21. Xu, H.N.; Li, L.Z. Quantitative redox imaging biomarkers for studying tissue metabolic state and its heterogeneity. J. Innov. Opt. Health Sci. 2014, 7, 1430020. [CrossRef]

22. Heikal, A.A. Intracellular coenzymes as natural biomarkers for metabolic activities and mitochondrial anomalies. Biomark. Med. 2010, 4, 241-263. [CrossRef] [PubMed]

23. Kolenc, O.I.; Quinn, K.P. Evaluating Cell Metabolism through Autofluorescence Imaging of NAD(P)H and FAD. Antioxid. Redox Signal. 2019. [CrossRef] [PubMed]

24. Ostrander, J.H.; McMahon, C.M.; Lem, S.; Millon, S.R.; Brown, J.Q.; Seewaldt, V.L.; Ramanujam, N. Optical redox ratio differentiates breast cancer cell lines based on estrogen receptor status. Cancer Res. 2010, 70, 4759-4766. [CrossRef] [PubMed]

25. Wen, Y.; Xu, H.N.; Privette Vinnedge, L.; Feng, M.; Li, L.Z. Optical redox imaging detects the effects of DEK oncogene knockdown on the redox state of MDA-MB-231 breast cancer cells. Mol. Imaging Biol. 2019, 21, 410-416.

26. Lin, Z.; Xu, H.N.; Wang, Y.; Floros, J.; Li, L.Z. Differential Expression of PGC1alpha in Intratumor Redox Subpopulations of Breast Cancer. Adv. Exp. Med. Biol. 2018, 1072, 177-181. [CrossRef]

27. Xu, H.N.; Nioka, S.; Li, L.Z. Imaging heterogeneity in the mitochondrial redox state of premalignant pancreas in the pancreas-specific PTEN-null transgenic mouse model. Biomark. Res. 2013, 1, 6.

28. Xu, H.N.; Feng, M.; Moon, L.; Dolloff, N.; El-Deiry, W.; Li, L.Z. Redox imaging of the p53-dependent mitochondrial redox state in colon cancer ex vivo. J. Innov. Opt. Health Sci. 2013, 6, 1350016. [CrossRef]

29. Walsh, A.J.; Cook, R.S.; Manning, H.C.; Hicks, D.J.; Lafontant, A.; Arteaga, C.L.; Skala, M.C. Optical metabolic imaging identifies glycolytic levels, subtypes, and early-treatment response in breast cancer. Cancer Res. 2013, 73, 6164-6174. [CrossRef]

30. Heaster, T.M.; Humayun, M.; Yu, J.; Beebe, D.J.; Skala, M.C. Autofluorescence imaging of 3D tumor-macrophage microscale cultures resolves spatial and temporal dynamics of macrophage metabolism. bioRxiv 2020. [CrossRef]

31. Phelps, D.S.; Umstead, T.M.; Floros, J. Sex differences in the response of the alveolar macrophage proteome to treatment with exogenous surfactant protein-A. Proteome Sci. 2012, 10, 44. [CrossRef] [PubMed]

32. Phelps, D.S.; Umstead, T.M.; Quintero, O.A.; Yengo, C.M.; Floros, J. In vivo rescue of alveolar macrophages from SP-A knockout mice with exogenous SP-A nearly restores a wild type intracellular proteome; actin involvement. Proteome Sci. 2011, 9, 67. [CrossRef] [PubMed]

33. Mikerov, A.N.; Haque, R.; Gan, X.; Guo, X.; Phelps, D.S.; Floros, J. Ablation of SP-A has a negative impact on the susceptibility of mice to Klebsiella pneumoniae infection after ozone exposure: Sex differences. Respir. Res. 2008, 9, 77. [CrossRef] [PubMed]

34. Mikerov, A.N.; Gan, X.; Umstead, T.M.; Miller, L.; Chinchilli, V.M.; Phelps, D.S.; Floros, J. Sex differences in the impact of ozone on survival and alveolar macrophage function of mice after Klebsiella pneumoniae infection. Respir. Res. 2008, 9, 24. [CrossRef] 
35. Mikerov, A.N.; Cooper, T.K.; Wang, G.; Hu, S.; Umstead, T.M.; Phelps, D.S.; Floros, J. Histopathologic evaluation of lung and extrapulmonary tissues show sex differences in Klebsiella pneumoniae-Infected mice under different exposure conditions. Int. J. Physiol. Pathophysiol. Pharm. 2011, 3, 176-190.

36. Mikerov, A.N.; Hu, S.; Durrani, F.; Gan, X.; Wang, G.; Umstead, T.M.; Phelps, D.S.; Floros, J. Impact of sex and ozone exposure on the course of pneumonia in wild type and SP-A (-/-) mice. Microb. Pathog. 2012, 52, 239-249. [CrossRef]

37. Mikerov, A.N.; Phelps, D.S.; Gan, X.; Umstead, T.M.; Haque, R.; Wang, G.; Floros, J. Effect of ozone exposure and infection on bronchoalveolar lavage: Sex differences in response patterns. Toxicol. Lett. 2014, 230, 333-344. [CrossRef]

38. Floros, J.; Hoover, R.R. Genetics of the hydrophilic surfactant proteins A and D. Biochim. Biophys. Acta (Bba) Mol. Basis Dis. 1998, 1408, 312-322. [CrossRef]

39. Phelps, D.S.; Umstead, T.M.; Floros, J. Sex differences in the acute in vivo effects of different human SP-A variants on the mouse alveolar macrophage proteome. J. Proteom. 2014, 108, 427-444. [CrossRef]

40. Phelps, D.S.; Umstead, T.M.; Silveyra, P.; Hu, S.; Wang, G.; Floros, J. Differences in the alveolar macrophage proteome in transgenic mice expressing human SP-A1 and SP-A2. J. Proteom. Genom. Res. 2013, 1, 2-26. [CrossRef]

41. Thorenoor, N.; Umstead, T.M.; Zhang, X.; Phelps, D.S.; Floros, J. Survival of Surfactant Protein-A1 and SP-A2 Transgenic Mice After Klebsiella pneumoniae Infection, Exhibits Sex-, Gene-, and Variant Specific Differences; Treatment With Surfactant Protein Improves Survival. Front. Immunol. 2018, 9, 2404. [CrossRef] [PubMed]

42. Thorenoor, N.; Zhang, X.; Umstead, T.M.; Scott Halstead, E.; Phelps, D.S.; Floros, J. Differential effects of innate immune variants of surfactant protein-A1 (SFTPA1) and SP-A2 (SFTPA2) in airway function after Klebsiella pneumoniae infection and sex differences. Respir. Res. 2018, 19, 23. [CrossRef] [PubMed]

43. Noutsios, G.T.; Thorenoor, N.; Zhang, X.; Phelps, D.S.; Umstead, T.M.; Durrani, F.; Floros, J. SP-A2 contributes to miRNA-mediated sex differences in response to oxidative stress: Pro-inflammatory, anti-apoptotic, and anti-oxidant pathways are involved. Biol. Sex. Differ. 2017, 8, 37. [CrossRef] [PubMed]

44. Wang, G.; Guo, X.; Diangelo, S.; Thomas, N.J.; Floros, J. Humanized SFTPA1 and SFTPA2 transgenic mice reveal functional divergence of SP-A1 and SP-A2: Formation of tubular myelin in vivo requires both gene products. J. Biol. Chem. 2010, 285, 11998-12010. [CrossRef] [PubMed]

45. Haque, R.; Umstead, T.M.; Ponnuru, P.; Guo, X.; Hawgood, S.; Phelps, D.S.; Floros, J. Role of surfactant protein-A (SP-A) in lung injury in response to acute ozone exposure of SP-A deficient mice. Toxicol. Appl. Pharm. 2007, 220, 72-82. [CrossRef]

46. Umstead, T.M.; Phelps, D.S.; Wang, G.; Floros, J.; Tarkington, B.K. In vitro exposure of proteins to ozone. Toxicol. Mech. Methods 2002, 12,1-16. [CrossRef]

47. Xu, H.N.; Feng, M.; Nath, K.; Nelson, D.; Roman, J.; Zhao, H.; Lin, Z.; Glickson, J.; Li, L.Z. Optical redox imaging of lonidamine treatment response of melanoma cells and xenografts. Mol. Imaging Biol 2019, 21, 426-435. [CrossRef]

48. Bartolome, F.; Abramov, A.Y. Measurement of mitochondrial NADH and FAD autofluorescence in live cells. Methods Mol. Biol. 2015, 1264, 263-270. [CrossRef]

49. Sunil, V.R.; Patel-Vayas, K.; Shen, J.; Laskin, J.D.; Laskin, D.L. Classical and alternative macrophage activation in the lung following ozone-induced oxidative stress. Toxicol. Appl. Pharm. 2012, 263, 195-202. [CrossRef]

50. Goldsmith, J.R.; Nadel, J.A. Experimental Exposure of Human Subjects to Ozone. J. Air Pollut. Control. Assoc. 1969, 19, 329-330. [CrossRef]

51. Mikerov, A.N.; Umstead, T.M.; Gan, X.; Huang, W.; Guo, X.; Wang, G.; Phelps, D.S.; Floros, J. Impact of ozone exposure on the phagocytic activity of human surfactant protein A (SP-A) and SP-A variants. Am. J. Physiol. Lung Cell Mol. Physiol. 2008, 294, L121-L130. [CrossRef] [PubMed]

52. Chuang, G.C.; Yang, Z.; Westbrook, D.G.; Pompilius, M.; Ballinger, C.A.; White, C.R.; Krzywanski, D.M.; Postlethwait, E.M.; Ballinger, S.W. Pulmonary ozone exposure induces vascular dysfunction, mitochondrial damage, and atherogenesis. Am. J. Physiol. Lung Cell. Mol. Physiol. 2009, 297, L209-L216. [CrossRef] [PubMed]

53. Sunil, V.R.; Francis, M.; Vayas, K.N.; Cervelli, J.A.; Choi, H.; Laskin, J.D.; Laskin, D.L. Regulation of ozone-induced lung inflammation and injury by the $\beta$-galactoside-binding lectin galectin-3. Toxicol. Appl. Pharmacol. 2015, 284, 236-245. [CrossRef] 
54. Cheng, W.; Duncan, K.E.; Ghio, A.J.; Ward-Caviness, C.; Karoly, E.D.; Diaz-Sanchez, D.; Conolly, R.B.; Devlin, R.B. Changes in Metabolites Present in Lung-Lining Fluid Following Exposure of Humans to Ozone. Toxicol. Sci. 2018, 163, 430-439. [CrossRef]

55. Mochitate, K.; Miura, T. Metabolic enhancement and increase of alveolar macrophages induced by ozone. Environ. Res. 1989, 49, 79-92. [CrossRef] [PubMed]

56. Ying, W.H. NAD(+)/ NADH and NADP(+)/NADPH in cellular functions and cell death: Regulation and biological consequences. Antioxid. Redox Signal. 2008, 10, 179-206. [CrossRef] [PubMed]

57. Simons, J.R.; Theodore, J.; Robin, E.D. Common Oxidant Lesion of Mitochondrial Redox State Produced by Nitrogen Dioxide, Ozone, and High Oxygen In Alveolar Macrophages. Chest 1974, 66, 9S-12S. [CrossRef]

58. Mudd, J.B.; Leh, F.; McManus, T.T. Reaction of ozone with nicotinamide and its derivatives. Arch. Biochem. Biophys. 1974, 161, 408-419. [CrossRef]

59. Brumaghim, J.L.; Li, Y.; Henle, E.; Linn, S. Effects of Hydrogen Peroxide upon Nicotinamide Nucleotide Metabolism in Escherichia coli: Changes in Enzyme Levels and Nicotinamide Nucleotide Pools and Studies of the Oxidation of NAD(P)H by Fe(III). J. Biol. Chem. 2003, 278, 42495-42504. [CrossRef]

60. Kunz, W.S.; Gellerich, F.N. Quantification of the content of fluorescent flavoproteins in mitochondria from liver, kidney cortex, skeletal muscle, and brain. Biochem. Med. Metab. Biol. 1993, 50, 103-110. [CrossRef]

61. Kunz, W.S. Evaluation of electron-transfer flavoprotein and alpha-lipoamide dehydrogenase redox states by two-channel fluorimetry and its application to the investigation of beta-oxidation. Biochim. Biophys. Acta 1988, 932, 8-16. [CrossRef]

62. Kunz, W.S.; Kunz, W. Contribution of different enzymes to flavoprotein fluorescence of isolated rat liver mitochondria. Biochim. Biophys. Acta 1985, 841, 237-246. [CrossRef]

63. Rehman, A.U.; Anwer, A.G.; Gosnell, M.E.; Mahbub, S.B.; Liu, G.; Goldys, E.M. Fluorescence quenching of free and bound NADH in HeLa cells determined by hyperspectral imaging and unmixing of cell autofluorescence. Biomed. Opt. Express 2017, 8, 1488-1498. [CrossRef] [PubMed]

64. Hou, J.; Wright, H.J.; Chan, N.; Tran, R.; Razorenova, O.V.; Potma, E.O.; Tromberg, B.J. Correlating two-photon excited fluorescence imaging of breast cancer cellular redox state with seahorse flux analysis of normalized cellular oxygen consumption. J. Biomed. Opt. 2016, 21, 60503. [CrossRef] [PubMed]

65. Byers, D.E.; Holtzman, M.J. Alternatively activated macrophages and airway disease. Chest 2011, 140, 768-774. [CrossRef] [PubMed]

66. Walsh, A.J.; Mueller, K.; Jones, I.; Walsh, C.M.; Piscopo, N.; Niemi, N.N.; Pagliarini, D.J.; Saha, K.; Skala, M.C. Label-free Method for Classification of T cell Activation. bioRxiv 2019. [CrossRef]

67. Murray, P.J.; Allen, J.E.; Biswas, S.K.; Fisher, E.A.; Gilroy, D.W.; Goerdt, S.; Gordon, S.; Hamilton, J.A.; Ivashkiv, L.B.; Lawrence, T.; et al. Macrophage activation and polarization: Nomenclature and experimental guidelines. Immunity 2014, 41, 14-20. [CrossRef]

68. Yuan, Y.; Yan, Z.; Miao, J.; Cai, R.; Zhang, M.; Wang, Y.; Wang, L.; Dang, W.; Wang, D.; Xiang, D.; et al. Autofluorescence of NADH is a new biomarker for sorting and characterizing cancer stem cells in human glioma. Stem Cell Res. Ther. 2019, 10, 330. [CrossRef]

69. Farhat, F.; Amerand, A.; Simon, B.; Guegueniat, N.; Moisan, C. Gender-dependent differences of mitochondrial function and oxidative stress in rat skeletal muscle at rest and after exercise training. Redox Rep. Commun. Free Radic. Res. 2017, 22, 508-514. [CrossRef]

70. Malorni, W.; Campesi, I.; Straface, E.; Vella, S.; Franconi, F. Redox features of the cell: A gender perspective. Antioxid Redox Signal. 2007, 9, 1779-1801. [CrossRef]

71. Celestino, I.; Checconi, P.; Amatore, D.; De Angelis, M.; Coluccio, P.; Dattilo, R.; Alunni Fegatelli, D.; Clemente, A.M.; Matarrese, P.; Torcia, M.G.; et al. Differential Redox State Contributes to Sex Disparities in the Response to Influenza Virus Infection in Male and Female Mice. Front. Immunol. 2018, 9, 1747. [CrossRef] [PubMed]

72. Noutsios, G.T.; Thorenoor, N.; Zhang, X.; Phelps, D.S.; Umstead, T.M.; Durrani, F.; Floros, J. Major Effect of Oxidative Stress on the Male, but Not Female, SP-A1 Type II Cell miRNome. Front. Immunol. 2019, 10, 1514. [CrossRef] [PubMed]

73. Thorenoor, N.; Kawasawa, Y.I.; Gandhi, C.K.; Floros, J. Sex-Specific Regulation of Gene Expression Networks by Surfactant Protein A (SP-A) Variants in Alveolar Macrophages in Response to Klebsiella pneumoniae. Front. Immunol. 2020, 11. [CrossRef] 
74. Durrani, F.; Phelps, D.S.; Weisz, J.; Silveyra, P.; Hu, S.; Mikerov, A.N.; Floros, J. Gonadal hormones and oxidative stress interaction differentially affects survival of male and female mice after lung Klebsiella pneumoniae infection. Exp. Lung Res. 2012, 38, 165-172. [CrossRef] [PubMed]

75. Gil, H.-W.; Oh, M.-H.; Woo, K.-M.; Lee, E.-Y.; Oh, M.-H.; Hong, S.-Y. Relationship between pulmonary surfactant protein and lipid peroxidation in lung injury due to paraquat intoxication in rats. Korean J. Intern. Med. 2007, 22, 67-72. [CrossRef]

76. Crowther, J.E.; Kutala, V.K.; Kuppusamy, P.; Ferguson, J.S.; Beharka, A.A.; Zweier, J.L.; McCormack, F.X.; Schlesinger, L.S. Pulmonary Surfactant Protein A Inhibits Macrophage Reactive Oxygen Intermediate Production in Response to Stimuli by Reducing NADPH Oxidase Activity. J. Immunol. 2004, 172, 6866-6874. [CrossRef]

77. McCubbrey, A.L.; Barthel, L.; Mohning, M.P.; Redente, E.F.; Mould, K.J.; Thomas, S.M.; Leach, S.M.; Danhorn, T.; Gibbings, S.L.; Jakubzick, C.V.; et al. Deletion of c-FLIP from CD11b(hi) Macrophages Prevents Development of Bleomycin-induced Lung Fibrosis. Am. J. Respir. Cell Mol. Biol. 2018, 58, 66-78. [CrossRef]

78. McQuattie-Pimentel, A.C.; Budinger, G.R.S.; Ballinger, M.N. Monocyte-derived Alveolar Macrophages: The Dark Side of Lung Repair? Am. J. Respir. Cell Mol. Biol. 2018, 58, 5-6. [CrossRef]

79. Atochina, E.N.; Beck, J.M.; Preston, A.M.; Haczku, A.; Tomer, Y.; Scanlon, S.T.; Fusaro, T.; Casey, J.; Hawgood, S.; Gow, A.J.; et al. Enhanced lung injury and delayed clearance of Pneumocystis carinii in surfactant protein A-deficient mice: Attenuation of cytokine responses and reactive oxygen-nitrogen species. Infect. Immun. 2004, 72, 6002-6011. [CrossRef]

80. Haque, R.; Umstead, T.M.; Freeman, W.M.; Floros, J.; Phelps, D.S. The impact of surfactant protein-A on ozone-induced changes in the mouse bronchoalveolar lavage proteome. Proteome Sci. 2009, 7, 12. [CrossRef]

81. Johannesson, M.; Ludviksdottir, D.; Janson, C. Lung function changes in relation to menstrual cycle in females with cystic fibrosis. Respir. Med. 2000, 94, 1043-1046. [CrossRef] [PubMed]

82. Fuentes, N.; Cabello, N.; Nicoleau, M.; Chroneos, Z.C.; Silveyra, P. Modulation of the lung inflammatory response to ozone by the estrous cycle. Physiol. Rep. 2019, 7, e14026. [CrossRef] [PubMed]

83. Delgado-Roche, L.; Mesta, F. Oxidative stress as key player in severe acute respiratory syndrome coronavirus (SARS-CoV) Infection. Arch. Med. Res. 2020, 51, 384-387. [CrossRef] [PubMed]

84. Smits, S.L.; de Lang, A.; van den Brand, J.M.A.; Leijten, L.M.; van Ijcken, W.F.; Eijkemans, M.J.C.; van Amerongen, G.; Kuiken, T.; Andeweg, A.C.; Osterhaus, A.D.M.E.; et al. Exacerbated Innate Host Response to SARS-CoV in Aged Non-Human Primates. PLoS Pathog. 2010, 6, e1000756. [CrossRef]

85. Koptides, M.; Umstead, T.M.; Floros, J.; Phelps, D.S. Surfactant protein A activates NF-kappa B in the THP-1 monocytic cell line. Am. J. Physiol. 1997, 273, L382-L388. [CrossRef]

86. Wang, G.; Umstead, T.M.; Hu, S.; Mikerov, A.N.; Phelps, D.S.; Floros, J. Differential Effects of Human SP-A1 and SP-A2 on the BAL Proteome and Signaling Pathways in Response to Klebsiella pneumoniae and Ozone Exposure. Front. Immunol. 2019, 10, 561. [CrossRef]

87. Jin, J.-M.; Bai, P.; He, W.; Wu, F.; Liu, X.-F.; Han, D.-M.; Liu, S.; Yang, J.-K. Gender Differences in Patients With COVID-19: Focus on Severity and Mortality. Front. Public Health 2020, 8. [CrossRef]

88. Thorenoor, N.; Kawasawa, Y.I.; Gandhi, C.K.; Zhang, X.; Floros, J. Differential Impact of Co-expressed SP-A1/SP-A2 Protein on AM miRNome; Sex Differences. Front. Immunol. 2019, 10, 1960. [CrossRef]

89. Floros, J.; Phelps, D.S. Is the role of lung innate immune molecules, SP-A1 and SP-A2, and of the alveolar macrophage being overlooked in COVID-19 diverse outcomes? PNEUMON 2020, 33, 1-5.

90. Tekos, F.; Skaperda, Z.; Goutzourelas, N.; Phelps, D.S.; Floros, J.; Kouretas, D. The Importance of Redox Status in the Frame of Lifestyle Approaches and the Genetics of the Lung Innate Immune Molecules, SP-A1 and SP-A2, on Differential Outcomes of COVID-19 Infection. Antioxidants 2020, 9, 784. [CrossRef]

91. Martinez-Sanchez, G.; Schwartz, A.; Donna, V.D. Potential Cytoprotective Activity of Ozone Therapy in SARS-CoV-2/COVID-19. Antioxidants 2020, 9, 389. [CrossRef] [PubMed]

92. Merad, M.; Martin, J.C. Pathological inflammation in patients with COVID-19: A key role for monocytes and macrophages. Nat. Rev. Immunol. 2020, 20, 355-362. [CrossRef] [PubMed]

(C) 2020 by the authors. Licensee MDPI, Basel, Switzerland. This article is an open access article distributed under the terms and conditions of the Creative Commons Attribution (CC BY) license (http://creativecommons.org/licenses/by/4.0/). 